\title{
Projeto Meninas na Computação - UNIFAP: relato de experiência e desafios
}

\author{
Patrícia Araújo de Oliveira, Aíla Maciel, Gabriela Felipa Souza \\ ${ }^{1}$ Departamento de Ciências Exatas e Tecnológicas - Universidade Federal do Amapá \\ araoli@unifap.br, ailamaciel@hotmail.com, gabriela.felipa@gmail.com
}

\begin{abstract}
The Meninas na Computação is an extension project at the Federal University of Amapa and aims both to encourage the female public to the interest in the field of Computing, and to present and discuss the main challenges faced by women in areas that have a majority of male performance. In this paper, we will show the strategies used for the actions carried out throughout 2019, mainly focused on the creation of a space that gives voice to those that do not feel represented on the field that they are, and also playful actions for female students from the 6th to the 9th grade of primary school. We will show a report on the main actions, as well as the challenges to be overcome.
\end{abstract}

Resumo. O Meninas na Computação é um projeto de extensão da Universidade Federal do Amapá e tem por objetivo tanto incentivar o público feminino ao interesse pela área da computação, como também apresentar e discutir os desafios enfrentados por mulheres em áreas que possuem a atuação majoritariamente do sexo masculino. Neste artigo, apresentaremos as estratégias utilizadas para as ações realizadas ao logo do ano de 2019, focadas principalmente na criação de um espaço que permita dar voz àquelas que não se sentem representadas no meio que frequentam e de ações lúdicas para alunas do $6^{\circ}$ ao $9^{\circ}$ ano do ensino fundamental. Apresentaremos um relato das principais ações, bem como os desafios enfrentados.

\section{Introdução}

Ao entendermos que a formação da sociedade brasileira é baseada no modelo patriarcal, o qual estabelece e hierarquiza de forma precisa os papéis masculinos e femininos, começamos a entender que os elementos constitutivos dos comportamentos esperados por cada um desses papéis são incutidos desde a infância até a fase adulta, e se fazem de maneira direta ou indireta. Em geral, o sexo masculino é estimulado para conduzir com destreza ações que desenvolvam sua agressividade, masculinidade, firmeza, autoestima e convicção, atuando no espaço público, que está destinado à sua liderança. Já o sexo feminino é educado para as funções naturais da maternidade e do espaço privado, cuidando do lar e dos que precisam dela, de modo que, mesmo quando estão no mundo corporativo, precisam estar enquadradas em profissões em que os empregadores elogiam suas qualidades femininas [Perrot 2005]. Todo esse contexto influencia não somente como mulheres deverão atuar, como também quais profissões irão seguir.

Em Whitmarsh et al. (2007) [Whitmarsh et al. 2007] foram entrevistadas mulheres em carreiras dominadas por mulheres. Elas indicaram que haviam sido desencorajadas a seguir carreiras neutras em termos de gênero por causa de percepções significativas de 
outras pessoas de que as mulheres não poderiam obter sucesso nessas áreas e gerenciar com êxito as responsabilidades de carreira e família ao mesmo tempo.

Sáinz Ibáñez et al. (2018) [Sáinz Ibáñez et al. 2018] apresentou as motivações que levam jovens a buscar carreiras em Ciência, Tecnologia, Engenharia e Matemática (STEM - Science, Technology, Engineering and Mathematics) e indicou que os participantes do sexo masculino associam a decisão de seguir os estudos em STEM a objetos específicos que os atraíram desde a infância, enquanto que os interesses das mulheres giram em torno das técnicas e processos associados ao seu campo STEM específico. O estudo ainda indica que os homens enfatizaram o papel da tradição familiar e da mídia de massa como influência da escolha da carreira. Os valores de utilidade social associados ao campo STEM eram o que mais influenciava as mulheres, enquanto os homens enfatizavam a obtenção de valores pessoais. O estudo ainda indica que as decisões que levaram as mulheres à busca da carreira STEM foram baseadas no incentivo de professores e professoras.

Nesse sentido, entendemos a importância do estímulo desde a infância, do incentivo e da representatividade na escolha da carreira. Por essa razão, o projeto Meninas na Computação atuou em 2019 diretamente com meninas de ensino fundamental, do $6^{\circ}$ ano ao $9^{\circ}$ ano, estimulando-as a realizar atividades ligadas à computação. Além disso, o projeto buscou incentivar a participação das alunas do curso de Ciência da Computação da Universidade Federal do Amapá (UNIFAP) na linha de frente das ações, e promoveu debates ligados ao tema, trazendo profissionais do sexo feminino para falar de suas experiências e desafios.

Apresentaremos, neste artigo, o relato da experiência do primeiro ano do projeto e os desafios a serem superados. O restante do trabalho está dividido como segue: na seção 2, explicaremos e apresentaremos as estratégias das ações já realizadas, como elas foram planejadas e executadas; na seção 3, apresentaremos os relatos de experiências das alunas do projeto; e, na seção 4, concluiremos discutindo o aprendizado obtido e os desafios a serem superados.

\section{Estratégias e ações realizadas pelo projeto}

\subsection{Participação das alunas de graduação}

Um dos objetivos do projeto é promover o incentivo e a representatividade. O curso de Ciência da Computação da UNIFAP conta apenas com uma professora no seu quadro, de modo que o fortalecimento da ideia de pertencimento a um lugar majoritariamente masculino é um aspecto essencial para que as alunas do curso possam se sentir motivadas. Dessa maneira, como primeiro passo para o projeto, foram feitos um levantamento e uma chamada a todas as alunas ativas no curso. Houve uma adesão muito significativa ao projeto e a atuação de todas foi de fundamental importância. A maioria atuou de forma totalmente voluntária, já que o projeto obteve no último ano apenas uma bolsa de extensão e nenhum outro auxílio financeiro. Algumas das atividades executadas por elas foram: divulgação do projeto; busca de apoio; planejamento e execução de atividades; organização de encontros; elaboração de material; e auxílio a outras alunas. Além disso, elas atuaram como monitoras das oficinas oferecidas às alunas do ensino básico. 


\subsection{Oficinas para alunas do ensino básico}

O projeto tem como perspectiva atuar na formação básica e introdutória em Computação junto às meninas do ensino básico. Para isso, foi escolhida a metodologia de ensino de Computação Desplugada [Rodrigues et al. 2018] e ferramentas VPL (Visual Programming Language). As inscrições aconteceram via internet, utilizando a ferramenta Google Forms. Houve 114 inscritas, e foram selecionadas 40 alunas do Ensino Fundamental II. Apenas 20 compareceram às oficinas, sendo estas de 12 diferentes escolas públicas de Macapá. As oficinas aconteceram na UNIFAP e foi utilizada a infraestrutura dos cursos de Engenharia Elétrica e Ciência da Computação da instituição.

Na primeira oficina, intitulada Oficina de Lógica de Programação, optou-se por ser realizada em dois momentos: no primeiro momento, foram organizadas duas dinâmicas para ensinar o pensamento computacional. A primeira foi chamada de dinâmica "Robozinho": para isso foi desenhado um percurso no chão e as alunas tinham como tarefa fazer com que uma das monitoras terminasse todo o percurso apenas obedecendo seus comandos. A segunda foi chamada de dinâmica "das bolachas": as alunas eram convidadas a passar o comando às monitoras de como preparar uma bolacha com geleia para comer. Ambas as dinâmicas foram guiadas por um roteiro pré-estabelecido. A segunda parte da Oficina de Lógica foi com a ferramenta Scratch [Resnick et al. 2009], e as alunas foram instruídas a criar um pequeno jogo com programação por blocos, que consistia na movimentação de um personagem que, ao tocar nos blocos inseridos no cenário, recebia pontos. O objetivo desse segundo momento foi introduzir o uso de programação por blocos, que seria utilizada nas duas outras oficinas.

Para as oficinas intituladas Oficina de Programação Android e Oficina de Programação Arduino, foram utilizadas ferramentas VPL. A ferramenta AppInventor [Kamriani and Roy 2016] foi utilizada para a Oficina de Programação Android e as alunas foram instruídas a construir um jogo na plataforma e depois utilizá-lo em um smartphone. O jogo é conhecido como MoleMash, em que a imagem de uma toupeira surge na tela em posições aleatórias, e o jogador recebe pontos ao tocar na imagem a tempo na tela do smartphone. Na criação do jogo, as alunas utilizaram sprites, procedimentos, blocos de texto, typeblocking, temporizadores e o componente relógio. Para a Oficina de Programação Arduino, as alunas foram instruídas à construção de um pequeno projeto - utilizando placas Arduino, protoboards, LEDs, resistores e jumpers - e à programação da ação "piscar o LED” - utilizando a ferramenta ArduBlock ${ }^{1}$.

Além disso, no primeiro contato com as alunas do ensino básico, foi feita uma apresentação, destacando diversas mulheres que atuaram na área da computação, além de uma discussão acerca do projeto e de qual é o seu principal objetivo.

\subsection{Eventos e debates sobre mulheres}

A organização de eventos faz parte dos objetivos do projeto e visa atender tanto a comunidade acadêmica quanto a comunidade externa, de todas as faixas-etárias e gêneros. Podemos citar três principais ações do projeto nesse aspecto: (1) o projeto teve como um dos focos a organização de palestras com mulheres que atuam em áreas predominantemente masculinas. Essas ações tiveram como objetivo a apresentação de projetos

\footnotetext{
${ }^{1}$ http://blog.ardublock.com
} 
e discussão sobre as jornadas no ambiente onde essas mulheres estudam e/ou trabalham; (2) as integrantes do projeto participaram de entrevistas e mesas-redondas envolvendo as temáticas "Mulheres na Ciência"e "Mulheres na Computação", sendo que, com relação a esta última temática, o projeto organizou uma mesa-redonda em um evento acadêmico da UNIFAP; (3) foi criado o "CINEMANA UNIFAP", cujas sessões de cinema visam apresentar filmes com temática feminina, seguidos de debate.

\section{Relato de Experiência}

Para o primeiro ano, o projeto apresentou um resultado positivo em todas as ações e frentes planejadas. Para o objetivo de participação das alunas de graduação visando o estímulo ao interesse, notamos um engajamento forte da maior parte das alunas ativas no curso, que trabalham de maneira voluntária com vistas ao sucesso do projeto. A Figura 1 apresenta alguns relatos das alunas de graduação participantes.
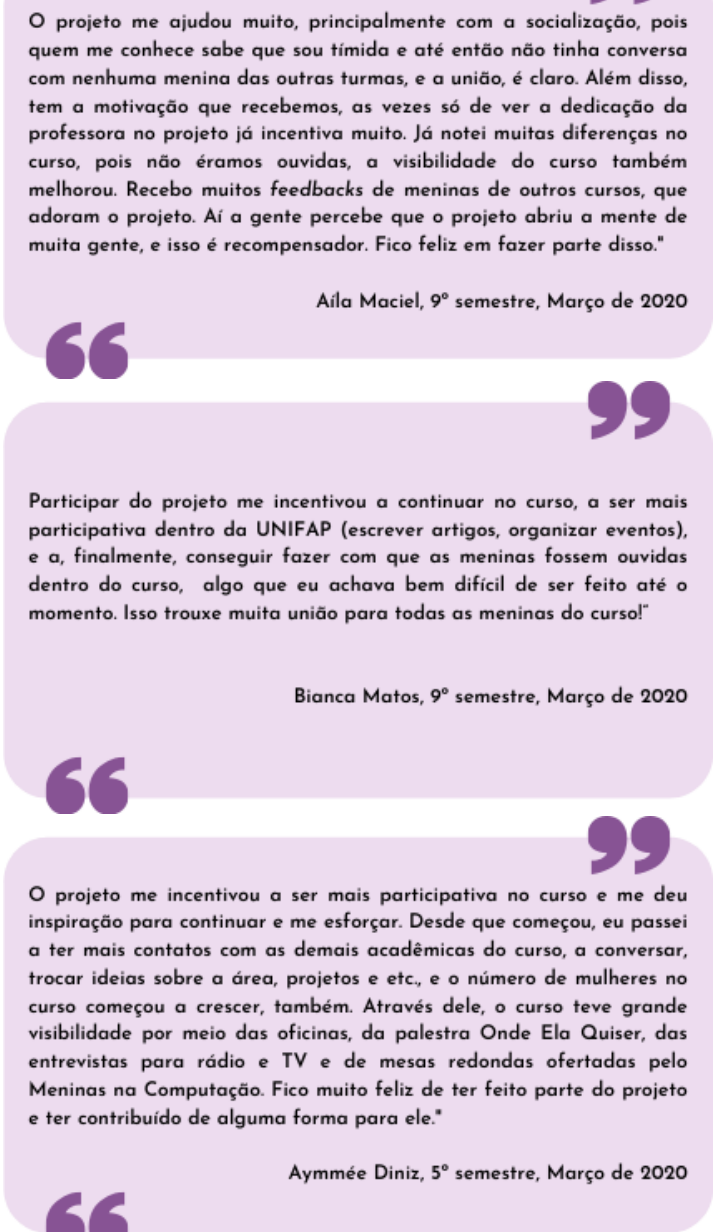

O projeto me fez ficar mais ativa no curso no ano passado, e é tăo bom sentir que você pertence a um lugar, que você precisa realmente fazer alguma coisa. Uma sala de aula com $\mathbf{4 0}$ homens não faz você se sentir assim. Com o tempo, o curso, as pessoas, foram parecendo mais acolhedoras, os eventos do projeto foram florescendo, e, de tanto esforço, surgiu uma iniciativa linda, que faz parte de uma cadeia nacional. Eu me sinto realmente privilegiada de poder fazer parte disso."

Gabriela Felipa, $7^{\circ}$ semestre, Março de 2020
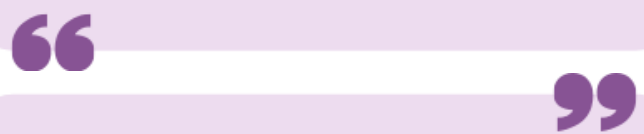

Participar do projeto me fez ter uma visão do quanto é necessária a existência de projetos como este. Ir as escolas e ouvir várias meninas nem ter ideia da existência do curso, e, ainda assim, mesmo sem perceber, terem uma afinidade com ele, é incrivel e triste ao mesmo tempol O impacto na minha vida foi que eu me senti acolhida num curso que eu realmente queria, mas que ouvia julgamento de todos os lados."

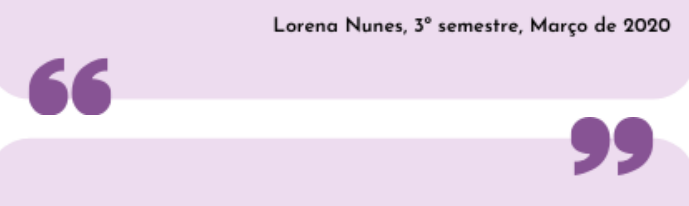

Participar do projeto me fez expandir meus horizontes e conhecer pessoas novas, além de eu ter criado novas experiências que ficarão para sempre na memória. Eu me senti acolhida, mesmo chegando 'atrasada' no curso, e é muito bonito ver o projeto unindo tantas 'pessoinhas' legais."

Amanda Albuquerque, $3^{\circ}$ semestre, Março de 2020

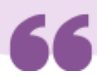

Figura 1. Relatos das alunas de graduação que participantes do projeto

As alunas do ensino básico responderam algumas perguntas feitas após a finalização das oficinas. Foi solicitado que elas indicassem, em uma escala de 1 a 5, o quanto gostaram de participar da oficina. $14,3 \%$ das alunas deram a nota 4 e $85,7 \%$ a nota 5. Além disso, foi perguntado se as oficinas despertaram o interesse das alunas na 
área da computação. $92,9 \%$ das alunas responderam que sim e 7,1\% responderam que as oficinas não despertaram o interesse pela área. Foi perguntado também se as alunas teriam interesse em participar de mais oficinas, mas com conteúdos mais avançados e mais atividades. $85,7 \%$ responderam que sim e $14,3 \%$ talvez.

\section{Conclusão}

Com o surgimento do projeto e, principalmente, após o primeiro evento, o "Onde Ela Quiser", verificou-se uma grande procura de professoras, professores, alunas e alunos da comunidade acadêmica com interesse em contribuir ou absorver a experiência como inspiração para a criação de outros projetos com o mesmo objetivo. As alunas do ensino básico e seus pais foram grandes entusiastas e contribuíram decisivamente para o seu sucesso. Já há grande procura por outras oficinas que possam ser oferecidas.

Quanto às oficinas ofertadas, o interesse foi grande da comunidade externa. Houve uma grande procura e, infelizmente, não foi possível atender a toda a demanda: foram 114 inscritas para 40 vagas disponíveis. A repercussão do oferecimento das oficinas deu visibilidade ao projeto e as alunas e a professora envolvidas passaram a participar de programas de rádio e TV para falar sobre o tema ${ }^{2}$. A repercussão auxiliou no outro objetivo do projeto que é promover o debate sobre mulheres na computação e na ciência.

Com a situação de isolamento devido à pandemia de Covid-19, as oficinas estão sendo remodeladas, assim como as ações de continuidade. Os desafios observados residem tanto no próprio processo de adaptação do conteúdo das oficinas e utilização de ferramentas que permitam atividades não presenciais, como também na infraestrutura tecnológica disponível no contexto local.

\section{Referências}

Kamriani, F. and Roy, K. (2016). App Inventor 2 Essentials. Packt Publishing Ltd.

Perrot, M. (2005). As mulheres e os silêncios da história. Bauru, São Paulo: EDUSC, 2005. Tradução Viviane Ribeiro.

Resnick, M., Maloney, J., Monroy-Hernández, A., Rusk, N., Eastmond, E., Brennan, K., Millner, A., Rosenbaum, E., Silver, J., Silverman, B., et al. (2009). Scratch: programming for all. Communications of the ACM, 52(11):60-67.

Rodrigues, S., Aranha, E., and Silva, T. R. (2018). Computaçao desplugada no ensino de programaçao: Uma revisao sistemática da literatura. In Brazilian Symposium on Computers in Education (Simpósio Brasileiro de Informática na Educação-SBIE), volume 29, page 417.

Sáinz Ibáñez, M., Fàbregues Feijóo, S., Rodó de Zárate, M., Martínez Cantos, J. L., Arroyo Prieto, L., and Romano Serrano, M. J. (2018). Gendered motivations to pursue male-dominated stem careers among spanish young people: A qualitative study. Journal of Career Development.

Whitmarsh, L., Brown, D., Cooper, J., Hawkins-Rodgers, Y., and Wentworth, D. K. (2007). Choices and challenges: A qualitative exploration of professional women's career patterns. The Career Development Quarterly, 55(3):225-236.

\footnotetext{
${ }^{2}$ Rádio CBN Amapá, Rádio UNIFAP, Rádio Tucuju e Canal Futura
} 